The viable decision maker for CAS survival: how to change and adapt through fitting process.

Carrubbo L., IAndolo F., Pitardi V., CAlabrese M

Luca Carrubbo, University of Salerno, Fisciano, Italy.

Francesca Iandolo, Sapienza University of Rome, Rome, Italy.

Valentina Pitardi, LUISS University Guido Carli, Rome, Italy.

Mario Calabrese, Sapienza University of Rome, Rome, Italy. 


\section{The viable decision maker for CAS survival: how to change and adapt through fitting process.}

ABSTRACT

Purpose - The purpose of this work is to investigate the decision making process in the management of the complex adaptive systems (CAS), particularly focusing on the dimensions that affect the individual decision maker (DM) when passing from decision to behaviour in fitting processes. Although the importance of the general process of fitting in terms of organizational design has been highlighted in earlier studies, a closer focus on the DM perspective is required.

Design/Methodology/approach - Starting from the theoretical frameworks of viable systems approach (vSa) and addressing the evolving concepts of change and adaptation in CAS, the work takes the DM perspective and investigates the dimensions involved in the paths that lead complex decisions into behaviors, when referring to fitting processes. The paper reviews the vSa and the concept of CAS, deepening the decision-making in fitting processes. Then, the paper proceeds to discuss the schemes and the categories that affect, at different levels, the decision and behavioural choices by proposing an interpretative framework.

Findings - The paper proposes a general framework useful to recognize/identify which are the elements/dimensions that have to be considered when organizations change in pursuing survival. The findings of the paper also show how adopting a vSa as a meta-model 
can be insightful to the understanding of service systems and useful in fully comprehending decision-making processes and behaviour in complex adaptive system.

Originality/value - The originality of this paper lies in exploring the decision making process in CAS, adopting a closer perspective on the single decision maker through the lens of the vSa.

Key words - Complex Adaptive Systems, Value Co-Creation, Decision Making, Change, Service Research, vSa.

Paper type - Conceptual paper 


\section{Introduction}

Nowadays rapid evolution in technology and resulting hypercompetition (D'Aveni, et al. 2010) requires organizations the capacity to adapt in order to survive. Indeed, the ability in changing and adaptation according to external contingencies represents the main keys to evolve and compete successfully.

Thus, in order to survive in the long run, every organization has to plan, lead and audit a lot of operations, affecting many elements of its structure; this requires new governance capacity, aimed at improving the ability to react to the external circumstances (Pels \& Polese, 2010).

According to a systems perspective, change depends on being part of a larger and interrelated system, called eco-system (Wieland et al, 2012), which suggests, flues, reacts, and matures expectations on action to amend the previous status for a different future, in accordance with a logic of co-evolution (Parente \& Petrone, 2010). Usually, change relates with the availability of more information, as well as to a different perspective in investigating phenomena, being often intended as a cognitive redefinition of the experience. In this sense, any influence of the elements of an organization (or system) contributes to the change of the system in its entirety (Watzlawick, Weakland \& Fisch, 1974). Furthermore, change could be seen as consequence of a learning processes and are strongly linked to the supplied values that belong to a specific organization and that act on the change processes by fostering or reducing them.

Hence, the fitting process enables the organizations to deal with the need to change and adapt to the solicitations coming from the external environment. Several past research has shown clearly that organizations naturally evolve their structure, management processes, human resource system and leadership behaviour to "fit" their business environment and strategy within that environment (Lawrence \& Lorsch, 1967; Beers, 2002). The most have examined the general process of fitting in the field of organizational studies, focusing on the 
dynamic that leads to specific configuration in terms of organizational design (Butler, 1991); others, have analysed the soft elements (culture, behaviours and routines) that can act as barriers to organizational effectiveness and performance (Beers, 1991). Yet, while research exists on the leader role and his capacity to manage and coordinate the required changes within the organization itself, closer insights are needed into the dimensions that affect the individual decision maker when passing from decision to behaviour with reference to adaptation process.

To this purpose, focusing closely on the decision maker perspective, the current work seeks to address this gap in understanding and deepening the schemes and categories that affect, with different depths, the path that leads from decision to behaviour in complex adaptive systems (CAS). In fact, by adopting a view that includes the whole context in which the organization operates, the role of the decision maker is crucial in influencing the evolutionary paths to adaptive behaviors and solutions.

Starting from a system perspective, the article adopts the Viable Systems Approach ( $v S a$ ) according to which every system is viable, its ultimate purpose is to survive, and its dynamics are guided by the presence of a decision maker (DM). The latter has a decisive role being able to orient the fitting processes that preserve the viability of the system by establishing and developing relations and interactions with all its entity of reference. Furthermore, the article addresses the fitting process in the management of Complex Adaptive Systems (CAS) relying on the considerations that both, their dynamic is not explained by linear paths and few variables (complex) and they are able to change and react to the external stimuli (adaptive). Therefore, the "fitness" capacity (Gell-Mann, 1995) allows these types of systems to survive in time and follow viable paths, namely those that guarantee their survival over time.

Given the opportunity gap in the literature, the present study contributes to service management and decision making studies providing an interpretative framework of the "decision to behaviour" paths in the individual decision maker, wherein is introduced the role 
of the Information variety owned by the DM, with the contextualization as constituting the process of implementation of generic decisions in actual behaviours. The work proposes that the contextualization process and the Information variety, defined by units, interpretation schemes and categorical values owned by the DM, play a relevant role in term of effectiveness and behavioural choices.

The article is structured as follow. In the literature review, the theoretical perspective of $v S a$ is introduced and the Complex Adaptive Systems are presented. Thereafter, the decisionmaking and the fitting processes are analysed particularly in the organizations intended as CAS. Finally, an interpretative framework is proposed. The article concludes with managerial implications, limitations and future research directions.

\section{Literature review}

\subsection{The $v S a$}

$\mathrm{vSa}$ is a theoretical framework for the analysis and interpretation of systems behaviors, derived from systems thinking and based on a constructivist approach.

According to vSa, (Golinelli, 2000; 2010; Barile, 2008; 2009) each entity (i.e. individual, community, and organization) can be described as a viable system (VS), whose ultimate purpose is to survive within its specific context of reference. Moreover, the constructivist approach considers that reality can not be intended as something objective, independent of the subject who experiences it, because it is the subject itself that creates, builds, invents what he believes that exists (Von Glasersfeld, 1984). This implies that, with specific reference to organizations, in analyzing phenomena, a central role is played by the subject that constitutes these organizations and orientates their processes, i.e. the decision maker. 
Stafford Beer (1972) firstly introduced the concept of VS as a system that survives, remains united and is integral, homeostatically balanced both internally and externally and possesses mechanisms and opportunities for growth and learning, development and adaptation, which allow it to become increasingly effective within its environment. Starting from this notion, vSa proposes some conceptual elements that partially differ from Beer's model. In fact, according to vSa, together with the analysis of the structural components, there is the analysis of the dynamics that qualify a system, always included within a context of reference that gives the system itself the possibility of learning, adapting and developing over time (principle of homeostasis: Von Bertalanffy, 1968; Beer, 1972; Barile, 2008). In fact, the ultimate purpose of survival that characterizes all the Viable Systems (VSs) is reflected in the change and adaptation processes of the system's components and elements that are needed in order to preserve its viability. First of all, with reference to Beer's model, the VS defined by vSa makes a strong distinction between decisions, identifying the ones related to "problem solving" issues and the ones related to "decision making" issues (Barile, 2009).

This distinction derives from the cognizance that the definition of "decision" as the proposal of a solution to a specific problem could be valid if the environment within the organization operates was basically stable and predictable in the short term. Today, however, the business environment is affected by an increasing number of complex phenomena, so that the variety and variability of elements to evaluate makes all the attempts to undertake decisions, strategies and behaviours useless (Barile \& Saviano, 2011). Terms as "complexity", "turbulence" and "entropy" have helped to change and redesign decision making processes, removing the classical rational and predictable perspective and highlighting the need to distinguish these two processes of choice.

The "problem solving" issues are usually linked to routines and known paths of resolution, and occur when the features, causes and conditions of a difficulty are known, and 
previous methodologies have been identified and tested, so that the choice is taken in a complicated environment (Barile, 2009).

The "decision making" issues, instead, are more linked to emergency and strategic thinking, and emphasize the fundamental role of the governing body (GB) (Golinelli, 2000); in fact, under conditions of complexity, that imply uncertainty, vagueness and ambiguity, the decision maker, who is required to preserve the viability of the system, cannot clearly identify all the variables and understand their interactions, as well as the expected cause-effect relationships (Barile, 2009).

From the above derives that the decision maker has to face several problem areas that require different resolution paths and various levels of knowledge. According to vSa, decision-making is affected by information and depends on the perception of the external context and on the information variety owned by each actor. Information variety, that can influence the cognitive alignment between the observing and the observed systems, can be defined by three dimensions, each one conveying specific properties (Barile, 2009, 2011; Calabrese, Iandolo \& Bilotta, 2011). Information Units represent the structural composition of knowledge made by a collection of data perceived by senses or defined by further autoelaborations of previous data, aimed at supporting decision processes. This dimension could be imagined as a datawarehouse of a VS and is strictly linked to two aspects: first, the collection of data relies on the context wherein actors are immersed, and it will change depending on the purposes of acting; second, the extent of a shared language will determine the level of understanding and full data captures.

The Information Units collected are organized and arranged to be able to be transformed from data to information. Interpretation Schemes represent how knowledge is shaped and allows building connections between data according to a specific purpose; they could be imaged as the data architecture that governs which data is collected and how it is stored and integrated. Using vSa language, interpretation schemes determine the transformation of 
blurred data into specific information depending on a particular context; they could cover different degree of specification, from a general vast matrix capable of rationalizing information (General Interpretation Schemes), to more specific structures of interpretation, through which it is possible to filter peculiar information (Synthesis Interpretation Schemes). In decision-making processes interpretation schemes hold an important role in achieving a possible consonance, both operational and decisional, between different VSs. Indeed, stated the fractal perspective of $\mathrm{vSa}$, from which derives that a community of people is a VS as well as a single person, it is possible to assume the existence of interpretation schemes to all the degrees that arise through the syntax, semantics and dictionary of shared languages. Accordingly, the language has the capability of building the conditions of a consonance within the same community or between communities that have similar characteristics, thus becoming a strategic resource in decision-making process.

\subsubsection{The conditioning factors of the Information Variety}

The way in which interpretation schemes are formed and used depends on categorical values, the value system of reference owned by a VS. They represent the subjective filter through which the interpretation schemes are customized and are usually shared between individuals belonging to specific social communities. Categorical values are the lens through which we look, understand and experience the world, helping to determine the degree of relevance and meaningfulness of different kind of knowledge. In this sense, categorical values are the stronger and deeper believes intervening in adaptation processes, responsible for the acceptance or refusal of change.

The notion of Information Variety derives from the identification made by vSa, of both a structural dimension — which is static and considers the parts and the relationships that exist among them-and a systemic dimension, that is dynamic and concerned with the identification of the interactions, while keeping into account the structural components 
themselves (Barile, Saviano, 2008; 2011). In this perspective, what matters, when referring to systemic entities, is firstly the condition of the relationship, and secondly that of the interactions, qualified on the basis of the concepts of consonance and resonance. Consonance and resonance represent, respectively, the potential and the consequent effects of harmonic interactions between two or more VSs.

Consonance identifies a condition of structural compatibility and/or complementarity between interacting entities and is more connected to the way of approaching a problem than to the amount of information. The possibility to have consonance between two or more VSs depends on the alignment of Categorical Values and Interpretation Schemes owned by each VSs. In particular, categorical values play a strategic role in Consonance variation, since they address to the adoption or refusal of a specific interpretation scheme, influencing the hypothesis selection of a problem. This means that the conditions of Consonance between two or more viable systems will be verified if not only the interpretation schemes are shared, but also, and more importantly, the strong beliefs (categorical values), continuing to increase when more information units are added.

Resonance is the notion related to the pre-existent conditions of consonance; it is what emerges from the systemic interaction between consonant entities. In other words, given the structural compatibility lying on the sharing of common values and schemes, Resonance represents the positive or negative 'acceleration' of Consonance during a new incoming information process.

From the above derives the fundamental role of vSa key concepts of consonance and resonance in orienting organizations behaviours; in fact, as said, the need of preserving viability conditions for a system is strictly linked to its ability to set up and develop the relationships established with the various entities that define its context of reference.

The contribution of vSa, therefore, underlines the importance of relation (identified by the structural compatibility defined by consonance) and interaction (identified by the systems 
dynamic defined by resonance), rather than connection, among actors; this shift is fundamental, also in orienting change and adaptation processes, as it calls for interaction and dynamism that overcome the only physical/monetary exchange, as it involves personal values and strong beliefs. In other words, when two decision makers are involved into a decision process, the stronger are mutual interests and shared values and schemes, the more there will be the chance to identify the needs and pursue the determinants of change. These conceptualizations are crucial with particular reference to change and adaptation processes; in fact, understanding how complex systems react to the external solicitations by modifying their structure can be useful to analyse which are the elements that persist within new configurations and which are the ones that mutate.

\subsection{CAS in a system perspective}

Trying to contribute to decision making and value co-creation advances in Service Research, it is helpful to start to show the two systems paradigms used to intend organizations as systems. In this section there is approach with studies on Complex Adaptive Systems (CASs) that worldwide are focusing on main features of design and functions of organizations, as mentioned all re-readable using the lens of vSa.

Some Authors stated many sentences of CAS in terms of structure, so this CASs are everywhere, including stock markets, human bodies and organs and cells, trees, and hospitals (Begun, Zimmerman, Dooley, 2003); examples of CAS include economies, ecologies, weather, traffic, social organizations, and cultures (Gell-Mann, 1994). The basic elements of organizations intended as CAS are the agents, just as semi-autonomous units able to valorize their own available resources and to evolve over time by developing model and personal behavior (Dooley, 1997). Recently some others authors proposed more practical definitions of CASs focused on their operations and activities; in this sense CASs are dynamic, massively entangled, emergent, and robust (Eoyang \& Berkas, 1999), they may be sensitive to certain 
small changes in initial conditions, and they are characterized by a dynamic state and exhibit emergent or self-organizing operations (Begun, Zimmerman \& Dooley, 2003), effectively adapting to a wide range of environmental change, giving them an "amazing resilience" (Marion \& Bacon, 2000:76). Finally, several authors deepened aspects of dynamic system interactions applied to CAS, highlighting that relationships in CASs are "complicated and enmeshed" (Eoyang \& Berkas, 1999:317), meanwhile the three fundamental processes can be identified in CASs: variation, interaction, and selection (Axelrod, Cohen, 1999). CASs are then characterized by a high level of connectivity, allowing the definition and evolution of a dynamic network of agents communicating and interacting constantly (Waldrop, 1992; Kelly, 1994; Coleman, 1999; Lissack, 1999; McKelvey \& Maguire, 1999).

Generally a number of studies converge on the point that many systems are complex but not all are adaptive (Dooley, 1996) and this meaning deserves to be investigated in order to deepen in what way decision makers could solve problems today, correctly reacting to external changes in order to maintain the appeal of value propositions over time. So this, many reflections made by scholars on CASs could affect the main pillars of system thinking and of vSa particularly, just like systemic adaptation, dynamic system interactions vs static relations and the dichotomy structure-system in organizations.

Following the system optic, as in the vSa, any organization intended as CAS has to interrelate with all of actors surrounding in the same environment, because «a system can be considered complex and adaptive when the system's agents have the possibility of continually adapting their actions in response to the environment and the behavior of the other agents» (Muffatto \& Faldani, 2003:84). In this way, also a service system (Spohrer et al 2007) or a service world (Bryson et al 2004) are CASs of people, and technologies working together to create value; there the presence of agents and the critical connections among them lead to continuous changes in CAS, as a result of the influencing external and internal forces (Begun, Zimmerman \& Dooley, 2003). 
Broadly, the adaptation of all systems existing in nature and artificial world concerns the incidence of supra-systems from which they are influenced (Golinelli, 2005; Barile, 2008). Every day, at every moment, each of us behaves thinks and compare because of the experiences that has developed over time, the background knowledge, the constraints that directly or indirectly affected by the context in which organizations are immersed (De Santo et al, 2011). From this point of view, the external influences have effects especially on decisions, actions, relationships and so on (Gummesson \& Polese, 2009; Mele, Pels \& Polese, 2010).

«CASs tend to maintain generally bounded behavior, sometimes called "attractor" regardless of small changes in initial conditions; as a result, CASs are robust and fitting. They exhibit the ability to alter themselves in response to feedback» (Begun, Zimmerman, Dooley, 2003:257). The Government of CAS must be able not only to organize the dynamic relationship between their components, but also to favor its own reproduction with actions to influence from out-side. In terms of decision-making, the ability to change its behavior as a function of external changes allows an organization to adapt in an ever more efficient way, fueling the chances of survival in the long term and helping to make its value proposition more sustainable (Barile et al, 2013a, 2013b).

The survival of a system, in fact, implies the persistence of its identity, which does not exclude change (Schein, 1990). In CAS the principle of self-learning focuses on retroactive effects of organizational processes, in order to reduce the entropy (Von Foerster, 1981) and its negative effects on efficiency; the related homeostasis in any kind of system allows to achieve and maintain equilibrium always in new states within limits of its structure (Hannan \& Freeman, 1977).

The system perspective was used since last decades in many paradigms and it seems to be helpful to really understand the evolution of all phenomena' effects found out. Studies on Tectology have dealt with processes and changes in terms of relationships with the outside; 
reacting to external changes can complicate internal relations, forcing a change in structure of any organizations, as push homogenisation with the outside; in these cases the concept of dynamic equilibrium (Bogdanov, 1988) seems to be adherent as well. In the past, the success or survival (and then competitiveness) could depend mainly on the ability to manage the routine, now it appears to be increasingly linked to the ability to innovate and manage innovation. In this sense, it is useful to make reference to the concept of resilience, or the ability of an organization to deal with the disturbances, over time maintaining a state of evolving equilibrium (Vicari, 1991). In the real life there are no "complexes" completely isolated now, since each of them is surrounded by an context, organized by other complexes, and other activities (Bogdanov, 1988). Today, being able to know and interpret the level of influences from the context, each organization can choose how to react and then adapt as defining the priorities for its actions. A system in equilibrium is able to retain its structure in a given context; organizational plasticity thus indicates the mobile and flexible character of the complex entity and its ability to group its entirety (Storbacka, 2011).

In a period of such strong global transformations, the rapid evolution of business organizations is conditioned by many environmental variables and the choice of supporting the development of the company by means of external relations allows for the flexibility that becomes essential to operate and make right decisions in an environment characterized by uncertainty.

\section{The nowadays relevance of "fitness".}

\subsection{The role of the Decision Maker in modern organizations}

From the above, it might be possible to refer to the theoretical perspective given by vSa and the notion of CAS by defining an organization as an entity that operates in complex 
contexts, that is able to adopt change and adaptation processes by putting in place actions aimed at its survival, in order to preserve its viability, that is the ultimate goal that every systemic entity has to pursue in its specific context of reference. According to this perspective, then, any system lives and its goal is to survive in a context populated by other viable systems that is subjectively perceived and defined by the decision maker within the general environment in which the system is immersed, on the base of the logic of consonance described above. In order to achieve this aim, the decision maker has to monitor and analyse the evolutions of the environmental conditions, to identify problem areas and, through a dynamic and continuous learning process, re-organizing and adapting his knowledge, in order to identify a solution and, finally, to take a decision.

When facing change and adaptation processes, then, the decision maker has the possibility to choose the adaptive solution identified as the more suitable to the specific problem, by defining the level of action to be taken: from a superficial and passive adaptation, up to a more significant and substantial re-configuration of the company that can involve its vision or its business idea. This means that the decision maker has the possibility to choose the adaptive solutions that are considered more suitable to each specific situation and that can require significant changes in the short and medium term, as well as only partial and gradual adjustments which, by focusing mainly on the components operating within the structure, enables him to make their strategic value emerge (Barile, et al, 2012a). These adjustments are characterized by the constancy of the organization structure considered, and, at the same time, by changes in the relations between the components that can be peripheral or non-strategic (Barile et al, 2012b; 2014; Badinelli et al, 2012). Sometimes, instead, environmental conditions stimulate changes that impact more on business characteristics, requiring actions of adjustment of the operating structure to a more significant extent (transformations and/or reconstruction) (Barile et al, 2012b). More frequently, the adjustments are not sufficient to 
ensure a balance between the needs and opportunities of the organization-context duo, and different actions are needed at the strategic level of the organization.

Due to the interaction with the other VSs, the learning and the adaptation process described above is affected, as said, by the information variety owned by every VS that participates, in an everlasting evolution and re-elaboration of knowledge configuration, involving both internal and external data, and being influenced by interpretation schemes and categorical values, that are the critical determiners in these complex choices. This process acts both in single VSs and between different VSs interacting each other; hence, adaptation and change require a re-shuffle of knowledge to a varying degree, that will produce an evolution of the information variety itself.

The characterization and optimization of the relations, the redesign of the organizational configurations, the management of complexity, identify different changing actions that can be analysed through modifications, reconfigurations and evolutions, and that can be better explained by making reference to the fitting processes. Fitting, as an adaptive set of actions (as seen in Fig. 1), can converge on different level of the system structure, with different level of depth; it depends on a combination of factors, regarding the strategies of the system (decisional area) and the constraints coming from the outside. Fitting helps to converge between demand and supply in a stated moment $\left(\mathrm{t}_{0}\right)$ and consists of the actions made by the Supply side to interpret and manage the needs of the Demand side, modifying something in the initial value proposition; this up-grade produces even new levels $\left(t_{0}+1\right)$ in production/provision. The decision maker has to choose, reminding the effects on the St and the consequences descending, in terms of change in financial fluxes, in HR's management, in production processes, in the business policies as well. The evaluation/correction process usually followed is cyclic: i) assess; ii) design; iii) implement; iv) monitor; v) evaluate; vi) adjust; vii) re-assess. 
Figure 1: Fitting flow

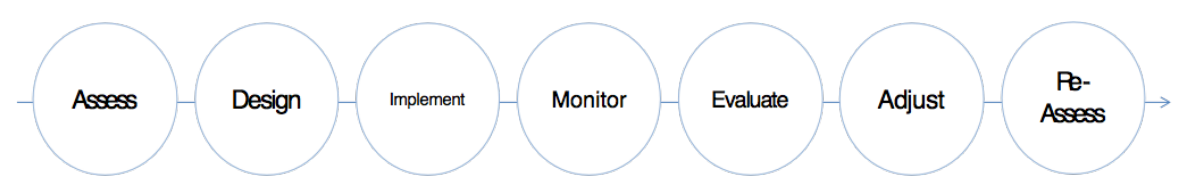

Source: Authors' elaboration (available on www.asvsa.org)

Each step can foster next one, by increasing in information, experience and knowledge of agents operating in the same value generation process, in which the multi-part contribution takes place and led to improvement in performances a higher level of quality proposed and perceived. It is not a chain as in the picture showed, but a reticular scheme of dynamic interactions, more difficult to manage.

\subsection{Addressing value co-creation}

Different effects come from fitting strategies and operations. In terms of value proposition, every provider must fit with evolving user's need, making adequate and coherent its solutions over time, especially in use (i.e. fitting process). As graphically represented below (see Fig. 2), the effective judge by final targets depends on the offer's capacity to adapt its own solution to the emerging changes, being to make the value proposition sustainable (Schein, 1990) and intending the value as the result of a personal perception of quality proposed and exchanged, while maintaining the appeal over time. 
Figure 2: Fitting process

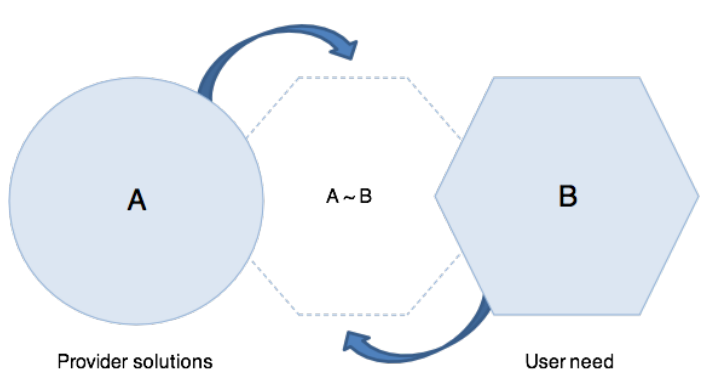

Source: Authors' elaboration (available on www.asvsa.org)

The choice of an offered value proposition by end-users occurs through a mechanism of purchase or use (value in use, Vargo \& Lusch 2004) as it triggers a process of value cocreation (Prahalad \& Ramaswamy, 2004; Ballantyne \& Varey, 2006; Grönroos, 2008). It implies the participation of multiple parties, thus making the value of a particular offer "effective" (up to that point, it was only "potential"). Indeed, in the picture above the provider solution $(A)$ and the user need $(B)$ can be matched $(A \sim B)$ toward something integrating asset, information and resources coming from both of interested sides, in a logic of collaboration, co-production, co-creation.

Another effect deriving from fitting processes deals with the value perception by users, as the opinion of any offer proposed is influenced by the personal judgment of the adherence to personal needs; the effective perception of customers (with respect to the existing alternatives) makes the solution offered valuable, as the value is in the use (Vargo \& Lusch, 2004; Chandler \& Vargo, 2011).

In this sense, value co-creation implies an active multi-actor contribution (Mele \& Polese, 2011), involving all the participants to the exchange in a particular offer and the concept of value certainly follows the logic of end-user's "effective" perception which is, therefore, subjective (Carrubbo, 2013), adjusting features and usefulness to customers' needs (as shown in Fig. 3). 
Figure 3: Fitting interactions

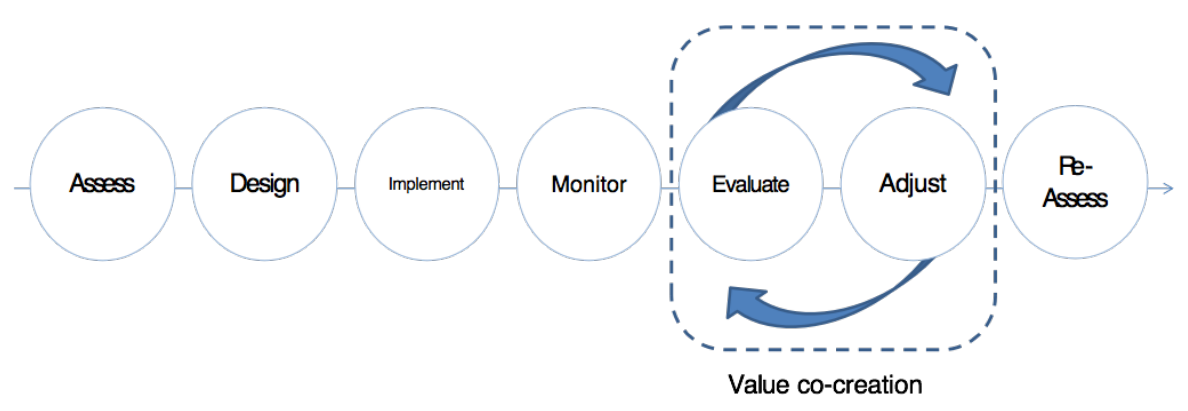

Source: Authors' elaboration (available on www.asvsa.org)

This continuous learning process is crucial in order to achieve effective positive results from fitting and to re-orient the needs and the tasks, re-assessing and re-organizing operations and available resources, on the base of both internal emerging fitting constraints and exogenous stimuli and solicitations. Subsequently, the fitting process allows the organization to update and change the value proposition in order to make it more competitive and preferable to similar solutions. Competitiveness may depend on the timeliness with which the organizations are able to change and to understand the signals coming from the other actors, thus, being able to adjust constantly the offer fosters viability through the construction of a durable competitive advantage.

Hence, the fitting process plays a strategic role in achieving survival and competitiveness, fostering value creation. Due to this relevant role, a deeper understanding of how the decision maker translates changing and adaption needs into actions is required.

\section{From decisions to behaviors}


The need to analyse how organizations change and adapt according to the solicitations deriving from the external environment is fundamental for the understanding of how decisions result in behaviors. Substantially, it is necessary to analyse how value categories and general schemes, according to the ultimate goal of survival, are contextualized within the specific behaviors of the organizations. This is linked to what has been said about the change and adaptation processes that lead organizations to new configurations that are deeply linked to the strong beliefs that characterize them. In fact, starting from the considerations above about decision making processes, together with the theoretical perspective of vSa, we propose an interpretative framework that could be useful to link how the intensity of change and adaptation processes, that leads from decision to specific behaviors, and that can be shown by the implementation of procedures, and routines within the organizations, can be linked to the three dimensions of the information variety owned by the decision maker, as described in par.2.2.

According to vSa, as said, the Categorical Values represent the strongest resistance or acceleration to change, and act - positively or not - on adaptation processes, while the schemes allow an understanding of these processes of adaptation and change, and, lastly, the information units give the decision maker more data about them. For these reasons, it is necessary to understand how deep is the change /adaptation required and on which dimensions and variables to act in order to preserve the viability of the system and grant its survival.

As every decisional process can be seen as the translation into something effective of a potentiality or of a will, that will be successively implemented through specific standards, we can make reference one of the main general schemes proposed by vSa, that distinguishes between will and act. In fact, act refers to realization, to completeness, and to a full definition, while the will refers to the ability to perform an action, even if it is not yet done (Barile, 2011). 
Figure 4: Will. Act. Norms - from 'abstract' to 'concrete'

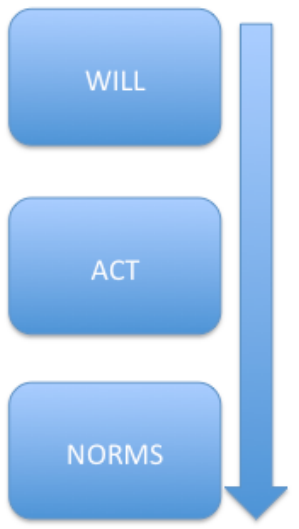

Source: Authors' elaboration (available on www.asvsa.org)

This distinction, combined with the current requirements that are imposed on the behavior of organizations and with the governing and management decisions, draws a further distinction, perhaps more suited to the study of philosophy, that is the one between ethics and morality.

These two terms, sometimes used synonymously, are also capable, however, of a different meaning. The Cambridge Dictionary of philosophy defines ethics as «commonly used interchangeably with 'morality', and sometimes it is used more narrowly to mean the moral principles of a particular tradition, group or individual». According to the second part of the sentence, we will intend that morality identify general typical behavioral patterns universally valid, while ethics define particular behavioral patterns that are usually valid within a specific context of reference.

Arguing that morality is the subject of ethics is to say that the general scheme (moral) is the object of the specific scheme (ethics); this second definition is coherent with the vSa perspective and that will be deepened in the following. In order to better specify what has been said, we can say that ethics can be traced back to a system of universal moral rules considered in a given historical context because generally shared and, for this reason, subject 
to change depending on the context of reference. Therefore, the definition that can be considered valid for the purposes of this study is one that sees morality as the total set of principles that lead towards the basic guidelines that direct the behavior of individuals and organizations, and then, towards aims that are subjectively recognized as positive. Ethics, then, can be defined as the contextualization, in behavioral terms, of these moral imperatives within the specific contexts that are defined by the individuals and the organizations that live them. Ethics, therefore, comes down to morality, as its declination in relation to specific historical moments and contexts.

Figure 5: Moral, Ethics, Laws - from 'abstract' to 'concrete'



Source: Authors' elaboration (available on www.asvsa.org)

By making reference both to the distinction between will and act and to the one between morality and ethics we can refer to a further one that distinguishes between capabilities and competences. Capabilities, in fact, can be defined as a potential that is developable in a variety of specific contexts producing a specific competence, whereas, then, competences can be defined as a capacity applied in one or more of all the possible contexts and in it is developed. Capabilities, therefore, are the expression of a potential, where the competences are, in turn, expression of effectiveness. 
Figure 6: Capabilities, Competences, Rules - from 'abstract' to 'concrete'

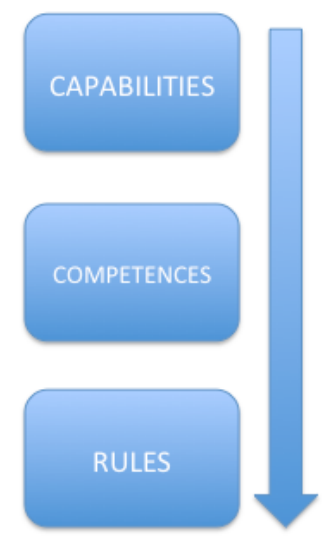

Source: Authors' elaboration (available on www.asvsa.org)

Within the business activities, these conceptualizations can be useful with reference to the basis of the decisions and choices of the individuals (managers and, more generally, decision makers) that act in organizations and that determine the specific context of reference. The moral orientation that inspires the decision-making processes, contextualized in ethical behaviors that derive from it, can be considered as the main expression of responsibility referred to business economy.

The definition of ethics identified above, detects relatively to the concepts of function and role of business and raises the question of which of the two should be considered ethical. Since, as mentioned, the context is defined by a subject in relation to a specific purpose which, according to the vSa, is survival- and ethics is, therefore, in turn defined in relation to a specific context, and is valid within it, the rules that guide the actions of an organization should be established with reference to this specific context in which the specific organization operates.

It appears useful to recall, at this point, the distinction among laws, norms, rules, and behaviors, which compose the last line of each column. Laws refer to the legislation with which the behavior of organizations and individuals are intended to be regulated and are typically gathered in a grouping of variable nature and reason, in order to orient specific 
conducts to certain conditions. The set of laws, and therefore the systematic organization (i.e. the "System") of the group, forms law.

For what concerns norms, they are generally treated as "rules of conduct", or to a command, which requires the individual to a particular behavior. Norms are not to be confused in any way with the law. In fact, while the law is a prescriptive act, norms are the result of this implementation. Norms are usually inferable from a written linguistic formulation (Constitution, regulation etc.) in order to give them a high degree of certainty and durability. The term rules means the declination, pro tempore shared, of a predetermined norm that is coded and coordinated with the others in an organic system (Barile, 2009).

From these considerations, then, it derives that the scope of the law deals with the actions of individuals and organizations, always intended within defined boundaries and systematized in a legal system; the norm, then, is the specification, in linguistic terms and using durable and generally recognized tools, of the law; the rule, finally, is the implementation, in behavioral terms, of the norm, as it emerges from procedures, models, protocols and operating techniques in common use. Substantially, within specific contexts, the rule can be understood as an application (subjectively interpreted) of the norm, giving rise to behaviors defined customs and traditions.

These conceptualizations are represented in Fig. 8 below: on the axis we reported two different conceptualizations that explain the evolution of the concepts, as the figure can be analyzed both from a horizontal and from a vertical perspective. For what concerns the vertical axis, 'from concrete to abstract' means that the elements go from specific to universal notions; for what concerns the horizontal axis, 'from general to specific' means that the elements, at each level, can influence each other. In fact, this horizontal transition shows the centrality of the process of contextualization and the relevance of the decision maker's Information variety in terms of effectiveness and behavioral choices (both of the individuals and of the organizations). 
Figure 7: An interpretative framework for the path 'decisions to behaviors' according to $v S a$ general schemes



Source: Authors' elaboration (available on www.asvsa.org)

In this regard, then, we included the last column of the figure, relative to decisions, choices and behaviors. Referring to what has been said so far about vSa, change and adaptation, and about the relevance of the strong beliefs, we can analyse how generic decision-making processes can evolve and be contextualized in specific behaviors. Starting from decisions, which, as said, can generally relate to both complex and simple issues, we can say that they will be transformed into specific behaviors in relation to the decision maker's information variety. In fact, each decision could evolve into a series of potential possibilities, which are represented by choices, which represent the set of alternatives that the decision maker has. However, through the contextualization process, which is made by the decision maker, it will be possible to identify the specific behaviors that translate the set of possible choices in actual behavior. The transition, then, from decisions to behaviors through choices 
develops on the basis of the decision maker's cognitive processes. This means that, in pursuing survival, each VS can adopt different behaviours, derived from different decisionmaking processes, that vary according to the information variety of each decision maker.

\section{Final considerations, managerial implications and future lines of research}

The paper addresses the gap in vSa literature about the analysis of the main dimensions that impact on changing and adaptation processes, when making reference to the decision maker in CASs. After presenting the theoretical lens of vsa applied to the analysis of CASs, the contribution focuses on fitting as the process that enables organizations to effectively respond to the external solicitations that could threaten the viability of organizations in the long run. In this sense, $\mathrm{vSa}$ is proposed as a perspective/meta-model/interpretative lens capable of identifying the dimensions that affect the decision maker when implementing decisions into behaviours within organizations. Accordingly, by making reference to the notion of vSa Information Variety and the dimensions that compose it, different levels and depths in the elements leading to change are proposed. The main contribution of this paper, therefore, relies in the proposal of a general framework that can be used for recognizing/identifying, which are the elements/dimensions that have to be considered when organizations change.

Several studies in Service Research show that modern organizations intending to respond effectively to the real needs in demand have to assume a service-centred approach, fitting with the requirements of the users they intend to serve (Pels \& Polese, 2010). The modern concept of service fosters a greater involvement of all the Actors in the process of value generation (including customers of course) and fosters a growing co-creative win-win process (Spohrer et al, 2007) Being able to modify its offer following external or internal changes, and promoting an innovative solution (when necessary), is the key for a sustainable success. 
In this sense, the paper proposes advances in service management research that focus on service systems and complex service systems, and specific implications for scholars can be drawn.

The present study sheds light on the complex and multifaceted nature of decision-making. By drawing on the vSa perspective, the paper opens up to a broader view of decision making that is grounded on system service (Badinelli et al., 2012) and looks at the Information variety dimensions as the fundamental elements that enable the fitting process.

Second, under a service perspective, fitting leads the convergence among applied competences (from suppliers) and value in use (from consumers), during all the steps of cocreation process, making offers sustainable and smart (Barile \& Polese, 2010; Napoletano \& Carrubbo, 2010). Further research could address the fitting process and the internal dynamic of the decision maker by integrating other service perspectives.

Third, under a systems perspective, fitting highlights the consonance between providers and users as the possible convergence among needs and solutions; the decrease of delta raises up the synergy, fostering resonance, by making offers perceived as valuable, thus positively acting on the ability of these organizations to survive in the long run. (Barile et al, 2013a) Further research could deepen the contribution of fitting process analysed through vSa lens to value creation processes that can foster systemic viability

Finally, a last set of implications comes out of the limits of the study. The paper is conceptual in nature and the interpretative framework proposed is a general scheme. Further research could address the application of the framework to the analysis of change and adaptation processes in other kind of organization. Further, the conceptual nature of this article provides preliminary insights for future empirical inquiry that is required for a deeper understanding of the issue.

Although this work is conceptual, it can offer some implications for practitioners. First, the understanding of mechanisms regulating the systems adaptive processes could help 
decision makers to make strategic decisions in complex environments. Second, 'fitness' allows these types of systems to survive over time. By providing a first framework of the main dimensions that have to be considered when organizations change, the article spurs managers to be aware of the level and depth of the change required through the fitting process. 


\section{References}

Axelrod, R., Cohen, M.D. (1999), Harnessing Complexity: Organizational Implications of a Scientific Frontier, New York. Free Press.

Badinelli, R., Barile, S., Ng, I., Polese, F., Saviano, M., Di Nauta, P. (2012), "Viable Service Systems and Decision Making in Service Management", in Journal of Service Management, vol.23, n.4, pp.498-526.

Ballantyne D., Varey R.J. (2006), “Creating value-in-use through marketing interaction: the exchange logic of relating, communicating and knowing", in Marketing Theory n. 3, pp.335-348.

Barile S. (2011), “A viable system conceived as a universal decision maker", in Various Authors, Contributions to theoretical and practical advances in management. A Viable Systems Approach (VSA), International Printing, Avellino.

Barile, S. (2009), Management Sistemico Vitale. Decidere in contesti complessi, Giappichelli, Torino.

Barile, S. (eds) (2008), L'impresa come sistema. Contributi sull'approccio sistemico vitale, II ed., Giappichelli, Torino.

Barile, S., Carrubbo, L., Iandolo F., Caputo, F. (2013a), 'From 'EGO' to 'ECO' in B2B relationships", in Journal of Business Market and Management, vol.6, n.4, pp.228-253.

Barile, S., Polese, F., Calabrese, M., Iandolo, F., Carrubbo, L. (2013b), "A theoretical framework for measuring value creation based on Viable Systems Approach (VSA)", in Barile, S. (eds), Contributions to theoretical and practical advances in management, Viable Systems Approach, ARACNE Ed., Rome.

Barile, S., Polese, F., Carrubbo, L. (2012a), "Il cambiamento quale fattore strategico per la sopravvivenza delle organizzazioni imprenditoriali”, in S. Barile, F. Polese, M.Saviano (eds), Immaginare l'Innovazione, pp.1-35. 
Barile, S., Polese, F., Saviano, M., Pels, J., Carrubbo L. (2014), "The contribution of vsa and sdl perspectives to strategic thinking in emerging economies", in Managing Service Quality, vol.24, is.6 pp.565-591.

Barile, S., Saviano, M. (2008), "Le basi del pensiero sistemico: la dicotomia strutturasistema," in L'impresa come sistema. Contributi sull'Approccio Sistemico Vitale (aSv), ed. Torino: Giappichelli, pp.63-81.

Barile, S., Saviano, M. (2011), "Foundations of systems thinking: the structure-system Paradigm", in AA.VV. (a cura di). Contributions to theoretical and practical advances in management - A Viable Systems Approach (VSA), International Printing, Avellino, pp. 125 .

Barile, S., Saviano, M. (2011). "Qualifying the concept of systems complexity", in VV.AA., Contributions to theoretical and practical advances in management. A Viable Systems Approach (VSA), ASVSA, Associazione per la ricerca sui Sistemi Vitali International Printing, Avellino. www.asvsa.org, pp. 27- 63, ISBN: 8878680109.

Barile, S., Saviano., M., Polese, F., Di Nauta, P. (2012b), "Reflections on Service Systems Boundaries: A Viable Systems Perspective. The case of the London Borough of Sutton”, in European Management Journal, n.30, pp.451-465.

Beer, M. (1991) Apple Computer: Corporate Strategy and Culture (Abridged): Case (A), Boston, MA, Harvard Business School.

Beer, M. (2002), Building Organizational Fitness in the 21st Century. Harvard Business School Working Paper, No. 02-044, January.

Beer, S. (1972), Brain of the Firm, The Penguin Press, London.

Begun, J.W, Zimmerman, B., Dooley, K. (2003), "Health Care Organizations as Complex Adaptive Systems", in S.M. Mick, M. Wyttenbach (eds.), Advances in Health Care Organization Theory. San Francisco, Jossey-Bass, pp.253-288. 
Bogdanov, A.A. (1988), Tectologia, Saggi di scienza dell'organizzazione, Edizioni Theoria S.r.1.

Bryson, J.R., Daniels, P.W., Warf, B. (2004), Service worlds: People, technology, organizations, Routledge, London.

Butler, R. (1991), Designing organizations: a decision-making perspective. London: Routledge, 1991.

Calabrese, M., Iandolo, F., Bilotta, A. (2011), "From Requisite Variety to Information Variety through the Information theory the management of viable systems". In Gummesson E., Mele C., Polese F. (eds.), Service Dominant logic, Network \& Systems Theory and Service Science. Giannini, Napoli.

Carrubbo, L. (2013), La Co-creazione di valore nelle destinazioni turistiche, ed. RIREA, Collana “Opera Prima”, n.2.

Chandler, J.D. Vargo S.L. (2011), “Contextualization and value-in-context: How context frames exchange", Marketing Theory, vol.11, n.1, pp.35-49.

Coleman, J.H., Jr. (1999), "What enables self-organizing behavior in businesses," in Emergence, vol.1, n.1, pp.33-48.

De Santo, M., Pietrosanto, A., Napoletano, P., Carrubbo, L. (2011), "Knowledge based service systems", in Gummesson, E., Mele, C., Polese, F. (eds), System Theory and Service Science: Integrating three perspectives in a new service agenda, Giannini, Naples, june 14-17.

Dooley, K. (1996), "A nominal definition of complex adaptive systems", in The Chaos Network, vol.8, n.1, pp.2-3.

Dooley, K. (1997), "A Complex Adaptive Systems Model of Organization Change," Nonlinear Dynamics, in Psychology \& Life Science, vol.1, n.1, pp.69-97. 
Eoyang, G.H. Berkas, T.H. (1999), "Evaluating Performance in a Complex, Adaptive System (CAS).” in Lissak, M.R. and H.P. Gunz (eds.), Managing Complexity in Organizations: A View in Many Directions, pp.313-335, Westport, CN. Quorum.

Gell-Mann, M. (1994), The Quark and the Jaguar. New York: Freeman \& Co.

Gell-Mann, M. (1995), The Quark and the Jaguar: Adventures in the Simple and the Complex, Henry Holt\&Co.

Golinelli, G.M. (2000), L'approccio sistemico al governo dell'impresa. L'impresa sistema vitale, I ed., CEDAM, Padova.

Golinelli, G.M. (2005), L'approccio sistemico al governo dell'impresa. L'impresa sistema vitale, Cedam, Padova.

Golinelli, G.M. (2010), Viable Systems Approach (VSA). Governing Business Dynamics, Kluwer (Cedam), Padova.

Grönroos, C. (2008), “Adopting a service business logic in relational business-to-business marketing: value creation, interaction and joint value co-creation", in Proceedings of the Otago Forum 2, pp.269-287.

Gummesson, E., Polese, F. (2009), “B2B is not an island!”, in Journal of Business \& Industrial Marketing, vol.24, n.5/6, pp.337-350.

Hannan, M.T., Freeman, J. (1977), “The population ecology of organizations”, in American Journal of Sociology, vol.82, n.5, pp.929-964.

Kelly, K. (1994), Out of Control: The New Biology of Machines, Social Systems, and the Economic World, Reading, MA. Addison Wesley.

Lawrence, P. R., Lorsch, J. W. (1967) Organization and environment, Boston, MA, Division of Research, Graduate School of Business Administration, Harvard University.

Lissack, M.R. (1999), “Complexity: The science, its vocabulary, and its relation to organizations," in Emergence, vol.1, n.1, pp.110-26. 
Marion, R., Bacon, J. (2000), "Organizational Extinction and Complex Systems.”, in Emergence, vol.1, n.4, pp.71-96.

McKelvey, B., Maguire, S. (1999), “Complexity and management: Moving from fad to firm foundations," in Emergence, vol.1, n.2, pp.5-49.

Mele, C., Pels, J., Polese, F. (2010), “A brief review of systems theories and their managerial applications", in Service Science, vol.2 n.1/2, pp.126-135.

Mele, C., Polese, F. (2011), "Key dimensions of Service Systems in Value-Creating Networks", in Demirkan, H., Spohrer, J., Krishna, V. (eds), The Science of Service Systems, Springer, pp.37-59.

Muffatto, M., Faldan,i M. (2003), "Realtà e prospettive dell'Open Source”, in Economia \& Management, vol.5, n.3, pp.83-100.

Napoletano, P., Carrubbo, L. (2010), "Becoming smarter: towards a new generation of services systems", in Impresa Ambiente e Management, vol.4, n.3, pp.415-438.

Parente R., Petrone M. (2010), "Strategie di Co-Evoluzione nei sistemi locali innovativi”, in Sinergie, n.83, pp.31-53.

Pels, J., Polese, F. (2010), “Configurational fit: Pathway for Successful Value Co-creation”, in Impresa, Ambiente, Management, Anno IV, n.3/2010, pp.355-373.

Prahalad C.K., Ramaswamy, V. (2004), The future of competition: Co-creating unique value with customers, Harvard University Press, Cambridge.

Schein, E.H. (1990), Cultura d'azienda e leadership, Guerrini e Associati.

Siggelkow, N. (2002), "Evolution toward Fit”, in Administrative Science Quarterly, 47: 125159.

Spohrer, J., Maglio, P.P., Bailey, J., Gruhl, D. (2007), "Steps Toward a Science of Service Systems", in Computer, vol.40, n.1, pp.71-77.

Storbacka K. (2011), On the plasticity of markets, in The Auckland Workshop on ServiceDominant Logic, Auckland, NZ, March 11-12. 
Vargo, S.L., Lusch, R.F. (2004), "Evolving to a New Dominant Logic for Marketing”, in Journal of Marketing, vol.68, pp.1-17.

Vicari, S. (1991), L'impresa vivente, Etas, Milano.

Von Bertalanffy, L. (1968), General System Theory. New York: Foundations, Development, Applications, George Braziller.

Von Foerster, H. (1981), Observing Systems, InterSystems Pubblication, Seaside.

Von Glasersfeld, E. (1984), “An Introduction to Radical Constructivism”, in Watzlawick P., The Invented Reality, Ed. P. New York, Norton.

Waldrop, M.M. (1992), Complexity: The Emerging Science at the Edge of Order and Chaos, New York. Simon \& Schuster.

Watzlawick, P., Weakland J.H., Fisch, R. (1974), Change. La formazione e la soluzione dei problemi, Astrolabio, Roma.

Wieland, H., Polese, F., Vargo, S., Lusch, R. (2012), “Toward a Service (Eco)Systems Perspective on Value Creation”, in International Journal of Service Science, Management, Engineering and Technology, vol.3, n.3, pp.12-25. 